\title{
Lead in teeth during the perinatal period
}

\author{
A. J. BuRKITT \\ M.Sc.
}

\author{
G. NICKLESS \\ Ph.D.
}

\author{
M. V. STACK \\ Ph.D.
}

M.R.C. Dental Unit, Bristol, and School of Chemistry, University of Bristol

IN a survey of the paediatric significance of environmental lead there was evidence that part of the maternal intake of lead may influence the fetus (Barltrop, 1969). Lead is incorporated in calcified tissues, and the studies of Altshuller, Halak and Landing (1962) and of Needleman, Tuncay and Shapiro (1972) indicate that the primary teeth provide evidence of lead exposure during infancy, a typical concentration being 10 p.p.m. The measurement of lead in developing teeth of fetuses would indicate uptake during the earliest period.

Local interest in the presence of industrial metals in the environment has been directed towards a variety of biological specimens. Lead, zinc, and cadmium are purified in the Severnside region, and these are included within the group of trace metals analysed in the various types of sample, usually by atomic absorption spectrophotometry. By the beginning of the eighth month of fetal life the more advanced primary teeth comprise sufficient partially calcified material to permit analysis of a number of trace metals by this method.

We undertook such analyses in developing teeth in order to determine whether there were any trends which might be related to fetal growth, as well as to pathological and other factors. This report deals principally with observations of the concentration of lead in fifty developing dentitions, with some reference also to lead content.

\section{Materials and methods}

The teeth included in the main series were obtained from forty cases of stillbirth and neonatal death, maturities being within 2 months of either side of full-term gestation (40 weeks). Reports by the pathologists included data on the duration of gestation, clinical histories of mother and fetus, and numerical data. The mean body weight was $3.0 \mathrm{~kg}$, the weight of the calcified portion of the dentition being $0.6 \mathrm{~g}$. Dentitions prepared for analysis formed a selected population, since it was intended to relate the findings to several arrangements of the data into groupings of comparable size: male/female, urban/ rural, stored/recent $(50 \%$ of these sets of developing teeth had been stored for more than 10 years). Other groupings of the data allowed examination of possible differences related to body weight, fetal age, and dentition weight. The proportion of samples for which the pathologies included 'central nervous system and/or other malformations' was increased above the usual frequency encountered in order to be able to note any trend in trace metal analyses which might be related to these pathologies. Division? into 'stored' and 'recent' groups refers to the avail- $\Omega$ ability of one group of twenty dentitions acquiredo during 1957 to 1963 for comparison with anothet acquired during 1972 to 1973 . Division into 'urban'? and 'rural' groups refers to an arbitrary grouping according to whether the mothers' addresses carried primary postal codes showing one digit ('urban') or two digits ('rural').

The opportunity also arose to study ten sets of developing teeth from fetuses delivered in Newcastle upon Tyne hospitals during 1973. Documentation was available for these specimens, referred to as the Tyneside group, the main series being designated as the Severnside group.

Developing teeth were dissected at autopsy with steel instruments, and the mineralized portions rinsed briefly in running water. They were dried at room temperature, weighed, and stored in polythene containers. Representative dentine and enamel samples were prepared from the incisors and first molars (the most advanced teeth) by separating the soft enamel from the hard dentine shell, using a blunt dental 'rosehead' bur. Weights of enamel and dentine were similar in each pair of samples prepared. The dry samples were weighed and dissolved in a high-grade perchloric acid $(5 \mathrm{ml} 70 \%$ $\mathrm{acid} / \mathrm{g}$ of enamel or dentine). After standing overnight, the glass-filtered samples were analysed by atomic absorption spectrophotometry. Standards and blanks were interposed frequently, as were samples from a pool of tooth fragments which gave 
TABLE 1. Lead concentrations in teeth during the perinatal period

\begin{tabular}{lcccc}
\hline Region & $\begin{array}{c}\text { Sample } \\
\text { dates }\end{array}$ & $\begin{array}{c}\text { Mean lead } \\
\text { concentration } \\
\text { p.p.m. }\end{array}$ & $\begin{array}{c}\text { Standard } \\
\text { deviation }\end{array}$ & $\begin{array}{c}\text { Number } \\
\text { of samples }\end{array}$ \\
\hline Severnside* & $1972-73$ & $38 \cdot 0(\mathrm{a})$ & $4 \cdot 7$ & 10 \\
(1st series) & $1957-63$ & $32 \cdot 3(\mathrm{~b})$ & $7 \cdot 4$ & 10 \\
Severnside* & $1972-73$ & $34 \cdot 0$ & $5 \cdot 9$ & 10 \\
(2nd series) & $1957-63$ & $28 \cdot 8$ & $6 \cdot 8$ & 10 \\
Tyneside & 1973 & $36 \cdot 8(\mathrm{c})$ & $7 \cdot 5$ & 10 \\
\hline
\end{tabular}

* Significant differences $(P<0.05)$ between 'stored' and 'recent' groups by Lord's test for groups of equal size (normal distributions) (a), (b), (c): See ordered individual values in Fig. 1.

analytical values for lead and zinc that were within $4 \%$ of those found by colorimetric methods. Replicate analyses agreed to within $2 \%$, and about $1 \%$ of the metal content of the filtrates was recoverable from the glass filters; however, no correction was made for this loss. Absolute values, and ratios of values for enamel and dentine within each dentition, were consistent with normal distributions.

\section{Results}

The developing dentition was found to contain about $20 \mu \mathrm{g}$ lead at full-term birth, when the calcified material present amounted to $0 \cdot 6 \mathrm{~g}$. Group mean lead concentrations were determined when the data were arranged according to sex, body weight, fetal age, dentition weight, and pathology (as defined above), also according to whether the maternal environment could be classified as urban or rural.

The non-significant differences resulting from comparisons of the above groupings were of the order of 1-2 p.p.m., the overall mean being 35 p.p.m. for the analyses of the first half of the series of samples, for which standardization was considered to have been more successful than that for the second half. These later samples were undertaken by another analyst, the values found being 3-4 p.p.m. less than those previously reported. However, in both cases a significant difference was observed when the groupings designated as 'stored' and 'recent' were compared. There was a mean interval of 12 years between the mean ages, and the mean lead concentration was 5-6 p.p.m. greater in the 'recent' group. Means and standard deviations are listed in Table 1. Only the first series of values have been shown in Fig. 1, in ascending order of magnitude, together with the 1973 Tyneside group. Severnside and Tyneside means were of the same order.

\section{Discussion}

The observation of greater lead concentrations in dentitions obtained recently than in those stored for a number of years points towards an environmental change. Whether or not the concentrations have

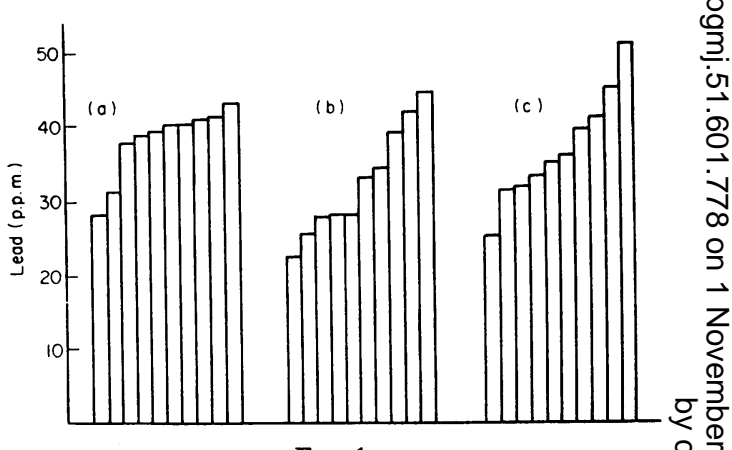

FIG. 1.

been determined with precision, or are consisten ov with normal distributions, the observed differences are significant also by a non-parametric test (MannWhitney $U$ test $; P<0.01)$. Furthermore, the corresponding analyses for zinc, cadmium, copper, manganese, nickel, and iron, to be reported elsewhere, do not show this type of difference at a significant level; nevertheless the same trend may be seen in all the above metals, particularly nickel In fact, the difference, for lead, of the same order as the standard deviation, is four times greater than the overall difference for the other metals, also expressed in terms of their standard deviations. Moreover, no difference was observed when the other factors were compared.

\section{Acknowledgments}

We thank Dr E. N. Hey for supplying Tyneside dentitions together with detailed autopsy reports. Mr D. J. Keech undertook the analyses of the dentitions for the second series.

\section{References}

Altshuller, L.F., Halak, D.B. \& Landing, B.H. (1962) Deciduous teeth as an index of body burdens of lead. Journal of Pediatrics, 60, 224.

BARLTROP, D. (1969) The transfer of lead in the human fetus. In: Mineral Metabolism in Paediatrics. Ed. by D. Barltrop and W. L. Burland, Blackwell, Oxford, p. 135.

Needleman, H.L., Tuncay, O.C. \& Shapiro, I.M. (1972) Lead levels in deciduous teeth of urban and suburban American schoolchidren. Nature. London, 235, 111. 